\title{
РЫHOK VSAT отвечает на вызовы COVID-19
}

Л.Павлова

DOI: 10.22184/2070-8963.2020.89.4.20.22

В рамках вебинара "Бизнес-диалог. Спутниковый интернет: VSAT vs COVID-19" производители VSATоборудования и операторы поделились опытом работы в условиях пандемии и самоизоляции, обсудили новые тренды на рынке спутникового ШПД в России и мире. Мероприятие было организовано ГП КС в партнерстве с интернет-порталом о спутниковом интернете в России KA-BAND.INFO.

\section{ТРЕНДЫ ОТ ВЕНДОРОВ}

Пандемия внесла свои коррективы в режим работы абсолютно всех участников рынка. Как рассказал заместитель генерального директора по развитию и эксплуатации систем связи ФГУП "Космическая связь" Евгений Буйдинов, на предприятии для сохранения здоровья сотрудников и развития бизнеса в период самоизоляции полноценно налажена дистанционная работа, в центральном офисе и на технических объектах даже оперативные совещания проходят по видеоконференцсвязи, соблюдается перчатно-масочный режим, периодически проводится дезинфекция помещений с полной обработкой всех предметов и поверхностей. К сотрудникам, которых по долгу службы невозможно "дистанцировать", - особое внимание. На технические объекты их доставляет и потом возвращает служебный транспорт, водители работают каждый день.

Что касается закупок оборудования, то, по словам Е.Буйдинова, благодаря долгосрочному планированию для ГП КС этот вопрос не стал критичным: "Если где-то что-то притормозилось на месяц-два - это не сильно чувствительно, поскольку мы имеем запас всех необходимых запчастей и материалов". Отдельно топ-менеджер предприятия поблагодарил партнеров за оперативную помощь в преодолении аварийной ситуации на спутнике "Экспресс-АМ6". Напомним, в марте технические службы ГП КС совместно с компаниями-партнерами организовали перевод центральной станции сети спутникового широкополосного доступа в Ка-диапазоне, которая ранее работала на космическом аппарате "Экспресс-АМ6", на спутник "Экспресс-АМУ1". Для переключения абонентов потребовалась настройка антенн на новый спутник. ГП КС благодарит отраслевое сообщество, включая представителей компаний "Евтелсат Нетворкс", "Ка-Интернет" и Hughes Network Systems, за содействие и помощь. "Приятно, что дружественное телекоммуникационное сообщество всегда помогает друг другу, несмотря на конкуренцию", - сказал Е.Буйдинов.

По словам представителей вендорских компаний, на технологические процессы производства VSAT-оборудования ситуация с COVID-19 не повлияла: ни на день они не останавливались у Hughes, Gilat, "Истар", iDirect. При этом все так или иначе испытали некоторые задержки при доставке продукции транспортными компаниями. Генеральный директор ООО "Истар" Павел Баканов сообщил, что в эпоху пандемии компания вошла с достаточным запасом маршрутизаторов на складе и никак не затормозила их поставку заказчикам. Более того, еще до пандемии "Истар", упреждая ситуацию, создал для своих сотрудников VPN-каналы для удаленной работы. "Вся команда разработчиков, подавляющее большинство инженеров-тестировщиков находятся по местам удаленной дислокации, но процессы ни на секунду не останавливаются, - отметил П.Баканов. - Завершен цикл разработки нового ПО и начат новый цикл разработки и ПО, и оборудования". По его словам, показатели продаж в России сохраняются примерно на том же уровне, что и в прошлом году, а вот глобальные продажи оборудования выросли на 25\%. Трендом нового времени П.Баканов считает рост спроса на техническую поддержку, что связано с дефицитом у заказчиков высококвалифицирован ного персонала, который может разбираться со 
сложным оборудованием. "У нас уже появилось несколько клиентов, которым требуется поддержка $24 \times 7,-$ сообщил П.Баканов. - Соответственно мы организовали службу международной технической поддержки, и это такой заметный тренд, который наряду с поставками оборудования дает свой вклад в наш бизнес".

Глава представительства Hughes Network Systems в России, СНГ и странах Балтии Константин Ланин отметил резкий рост спроса на спутниковую связь в сегменте В2С именно в период пандемии. В Бразилии, например, за два месяца было подключено 10 тыс. новых абонентов, а в Северной Америке Hughes впервые пошел на беспрецедентный шаг: компания приостановила рекламу продвижения продаж, ограничивая постоянно растущий спрос. На рынке физических лиц рост налицо в Латинской Америке, Северной Америке и Юго-Восточной Азии, отметил К.Ланин. В то же время явно происходит спад на корпоративном рынке. Связано это с тем, что те или иные компании были вынуждены приостановить или даже свернуть свой бизнес, а также с ограничениями в движении. Константин Ланин выразил надежду на достаточно быстрое восстановление спроса в этом сегменте рынка. Он выделил еще один тренд нового времени: решая старую проблему цифрового неравенства, сейчас на арену вышли VSAT коллективного пользования. Мексика в лице своего телекома, практически, финансирует строительство хотспотов Wi-Fi, оборудуя ими порядка 4 тыс. деревень. За 50 центов в час пользователь может получить доступ в интернет, по скайпу связаться со своими близкими, сделать онлайн-закупки или транзакции. ARPU от такой точки ожидается примерно 120 долл. в месяц. "Инициатива достаточно широко шагнула по Латинской Америке и ЮгоВосточной Азии, - сообщил К.Ланин. - Это интересный сегмент, для которого мы видим отличную перспективу".

Рост консьюмерского рынка отметил и генеральный директор "Гилат Сателлайт Нетворкс (Евразия)" Денис Стафеев. В период пандемии в России Gilat поставил порядка 2 тыс. VSATкомплектов в месяц, и эти темпы сохранятся еще несколько месяцев. Оценить текущую ситуацию в В2В-сегменте Д.Стафеев считает затруднительным, поскольку крупные корпорации и госсектор используют долгосрочные контракты. А вот предположить определенную стагнацию в будущем вполне возможно, потому что в этом году коммерческие структуры станут сокращать бюджеты.
Рост продаж VSAT-оборудования в России и странах СНГ в полтора раза за минувший квартал по сравнению с аналогичным периодом прошлого года отметил директор по продажам в России и СНГ VT iDirect Никита Демиденко. "Обычно начало года - спокойное, лето - спящее, а четвертый квартал - взрывной, - прокомментировал он сложившуюся ситуацию. - В этом году первые два квартала бьют все нормы. Возможно, это связано с тем, что в условиях пандемии связь нужна всем обязательно, от этого никуда не денешься".

\section{ТЕНДЕНЦИИ ОТ ОПЕРАТОРОВ}

Насколько повлияла пандемия на трафик VSAT-сетей? В своих ответах на этот вопрос представители операторских компаний разошлись во мнениях. Так, акционер "Ка-Интернет" Сергей Пехтерев заметных изменений в трафике корпоративного сектора не отметил, поскольку бюджеты крупных заказчиков на 2020 год были сформированы раньше. При этом он выделил новую тенденцию - это усиление конкуренции в сегменте предоставления услуг Ka-band. С С.Пехтеревым согласились коммерческий директор ГК "РТКомм" Михаил Муттерперл и директор по развитию бизнеса Orange Business Services в России и СНГ Алексей Антоненко. Сам факт отсутствия падения выручки можно расценивать как уже хорошую новость, считает А.Антоненко. Он подчеркнул, что отечественный рынок связи на судах стабильно развивается и во время пандемии, все суда ходят в обычном режиме, и оператор получает запросы на расширение каналов. Сектор maritime VSAT, на его взгляд, не останавливался и показал себя стабильным.

В то же время председатель совета директоров АО "КБ "Искра" Андрей Ромулов отметил немаловажную тенденцию: удаленная работа прежде всего изменила структуру потребления графика. "Прямые каналы загружены в большей степени, потому что выше востребованность различных мессенджеров, видеосвязи, видеоконференций, - пояснил А.Ромулов. - Мы отмечаем ежемесячный рост порядка 10-15\%. Очень небольшое количество клиентов, которые находятся в пограничном состоянии, отказываются от услуг, очень многие просят различные скидки - но тем не менее трафик растет". Некоторой статистикой периода пандемии в сравнении допандемийным поделился директор департамента развития Dozor-Teleport Сергей Медведев. По его данным, в секторе В2В все в целом стабильно. Исключение составляют компании, которые занимаются добычей углеводородов и минералов, а также их дочерние структуры - старатели и другие вахтовики. У них отмечается падение трафика 
на 30\%. Но здесь ведущую роль, скорее, сыграла даже не пандемия, а соглашение о сокращении добычи нефти ОПЕК+. Некоторые компании были вынуждены либо уйти из России, либо свернуть свой бизнес, либо сократить свои бюджеты. В секторе В2О изменений нет, зафиксирована полная загрузка каналов операторов; были получены запросы на расширение, работы выполнены. Регулируемый контрактами госсектор В2С стабилен; были запросы на расширение каналов, работы выполнены. А вот в сегменте В2С зафиксирован уверенный рост в 20\%, что компенсировало частичный провал в корпоративном секторе. Также отмечается рост запроса на интеграцию и дополнительные сервисы.

\section{ЧТО ГОД ГРЯДУЩИЙ НАМ ГОТОВИТ?}

В качестве заключительного вопроса участники круглого стола обсудили перспективы развития рынка VSAT. Амплитуда прогнозов - от сдержанного скептицизма до уверенного оптимизма. Приводим практически дословно.

С.Пехтерев. Это как предсказать цену на нефть. Будем надеяться на лучшее.

М.Муттерперл. Ничего критичного не произойдет. А предугадать, что будет в долгосрочной перспективе с точки зрения бюджетов государственных органов и нефтяников - очень сложно.

А.Ромулов. Период восстановления зависит от размеров страны. Предыдущие кризисы показали, что Россия восстанавливается в среднем за два года, но сейчас ситуация несколько иная. Основные наши клиенты - это достаточно крупные предприятия и госсектор. Я думаю, ничего критичного не произойдет.
С.Медведев. Нам очень хотелось бы, чтобы сектор "нефтянки" восстановился как можно скорее, и курс доллара стабилизировался. И тогда спутниковым операторам в ближайшее время ничего не грозит.

А.Антоненко. Скорость восстановления зависит от того, насколько операторы быстро думают и принимают решения. В спутниковой связи операторы пережили столько всевозможных историй, связанных с дефицитом ресурса, невзлетами спутников, ограничениями со стороны регулятора, что мозг ни на секунду не расслаблялся. Поэтому в этой ситуации, когда нужно быстро принять решение и перестроиться, подавляющее большинство к этому готово. А значит, есть уверенная надежда, что мы будем продолжать работать, искать новые рынки и развиваться.

К.Ланин. Телекоммуникации - наименее уязвимый в пандемии сектор рынка. Парадокс в том, что во все кризисы, которые сотрясали мир в прошлые десятилетия, только одна отрасль показывала рост. Это телекоммуникации и, в частности, спутниковая связь. Поэтому у меня позитивные мысли о дальнейшем развитии.

Д.Стафеев. Долгосрочная перспектива зависит от государства. Как наше государство будет себя чувствовать - так будет себя чувствовать и отрасль космической связи.

Д.Демиденко. Связь сейчас необходима наравне с хлебом. Человек, купивший хлеб, купит себе и телефон, и интернет. Поэтому именно в условиях кризиса связь будет наиболее востребована. П.Бакланов. Я оптимист. Пережившим кризисы мозги не дают расслабиться.

\section{Ксения Дроздова переизбрана председателем Эксплуатационного комитета "Интерспутника"}

Решением Эксплуатационного комитета Международной организации космической связи (МОКС) "Интерспутник" его председателем вновь избрана Ксения Дроздова, заместитель генерального директора по развитию бизнеса ФГУП "Космическая связь". Ее полномочия продлятся в течение трех лет начиная с 15 июня 2020 года.

В сферу деятельности Эксплуатационного комитета "Интерспутника" входит оперативное рассмотрение и решение вопросов деятельности организации. Членами комитета являются 25 участников из числа организаций связи, назначенных странами-членами "Интерспутника". Организация осущест- вляет эксплуатацию международной системы спутниковой связи, предоставляет телекоммуникационным операторам и корпоративным пользователям частотно-энергетический ресурс на геостационарных спутниках связи, а также оказывает комплексныеуслуги в области создания и использования сетей спутниковой связи.

В рамках долгосрочного сотрудничества со ФГУП "Космическая связь" "Интерспутник" предлагает клиентам услуги на российских космических аппаратах серии "Экспресс". Организация имеет статус официального дистрибьютора спутникового ресурса и услуг европейского спутникового опе- ратора Eutelsat, осуществляет маркетинг и продажу спутниковой емкости систем ABS, Intelsat, "Газпром космические системы", Azercosmos, а также сотрудничает с другими региональными и национальными операторами спутниковой связи.

Пользуясь статусом межправительственной организации, "Интерспутник" заявил собственный орбитально-частотный ресурс в ряде позиций на геостационарной орбите, который используется для реализации совместных с заинтересованными партнерами проектов по созданию новых систем спутниковой связи.

По информации МОКС "Интерспутник" 


\title{
ИЗДАТЕЛЬСТВО «ТЕХНОСФЕРА» ПРЕДСТАВЛЯЕТ КНИГУ:
}

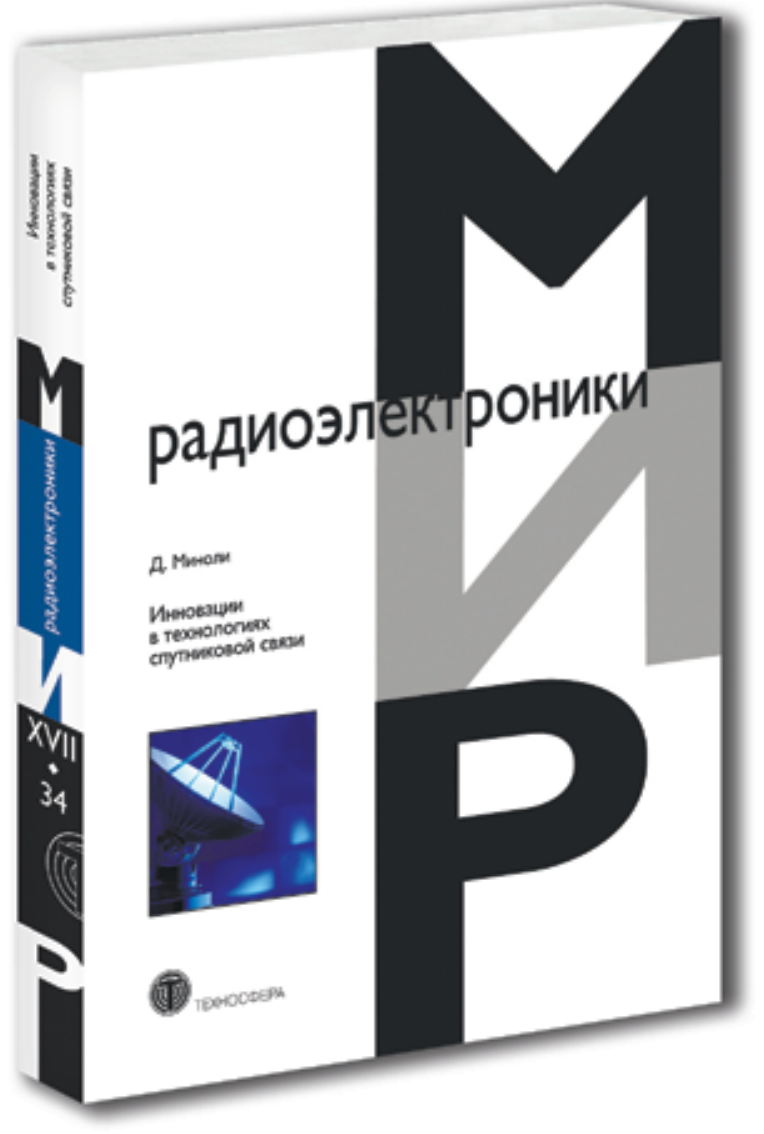

А. Миноли

\section{ИННОВАЦИИ В ТЕХНОАОГИЯХ СПУТНИКОВОЙ СВЯЗИ}

\author{
при поААержке \\ Фимиала АO «ОРКК» - «НИИ КП»
}

M.: TEXHOCФЕPA, 2019. - 446 c.,

ISBN 978-5-94836-545-9

Цена 1188 руб.

Книга является обзором Ключевых Аостижений в области Коммерческой спутниковой связи. В ней ставится вопрос о том, какими могут быть новые возможности Аля конечных пользовате^ей и поставщиков услуг в использовании новейших быстроразвивающихся инноваций в этой области (расширение спецификации DBV-S2 (DVS-S2X)), технологий спутниковых каналов с высокой пропускной способностью (HTS, High throughput satellite), метоАОв спутникого применения решений М2M (machine-tomachine) и т. А.).

Книга соАержит 8 глав, перечни источников, малоАоступных ряАовому русскоязычному читателю (исключительно на английском языке), три приложения и преАметный указатель.

Вводная глава содержит справочный технический материал, который может быть полезен инженерам по спутниковой связи вне зависимости от остального соАержания Книги. В частности, в этой главе привеАены свеАения о наименованиях радиодиапазонов, используемых в спутниковой связи, а также околоземных орбит спутников космической связи (не только геостационарных). В приложении В привеАен ГАоссарий основных концепций и терминов спутниковой связи. ОН созАан на основе различных источников в ограниченном объеме инфрормации с привеАением ссылок на эти источники.

ИзАание Можно считать справочным пособием, так Как в ввоАную ГАаву вкАючен справочный технический материал, который будет служить в качестве учебника по спутниковой связи А^я начинающих.

\section{Как заказать наши книги?}

По почте: 125319, Москва, а/я 91

По факсу: (495) 956-33-46

E-mail: knigi@technosphera.ru 